\title{
DISCUSSÃO SOBRE O ENVELHECIMENTO COMO INSTRUMENTO PARA EDUCAÇÃO EM SAÚDE NO ENSINO DE HISTÓRIA
}

\author{
DISCUSSION ON AGING AS AN INSTRUMENT FOR HEALTH EDUCATION \\ IN HISTORY TEACHING
}

Luciane Pedro ${ }^{1}$

\begin{abstract}
RESUMO: A população brasileira alcança índices cada vez mais elevados de idosos. Este fato nos remete à reflexão sobre a importância desse tema nas abordagens de educação em saúde no ensino de História. Considerando-se saúde entendida como um direito humano fundamental e como algo que construímos ao longo de nossa vida, condicionada às condições sociais, econômicas e emocionais que nos acompanharam, o objetivo do presente artigo é apontar questões relativas à importância da discussão sobre o envelhecimento de forma associada à educação para a cidadania. Utilizamos como metodologia a revisão bibliográfica sobre o assunto, apoiando-nos na construção das categorias teóricas, saúde e educação para a cidadania, a partir dos referenciais desenvolvidos por Benevides e as propostas pedagógicas libertadoras, cuja construção teórica teve como referência o educador Paulo Freire. A inclusão da temática do envelhecimento como instrumento para Educação em Saúde no ensino de História possibilita pensarmos em indivíduos comprometidos com a sua saúde e da coletividade, bem como, com a afirmação da vida digna para todos e com a edificação de uma sociedade de respeito aos direitos humanos.
\end{abstract}

Palavras-chave: Envelhecimento. Educação em saúde. Cidadania. Ensino de história.

\begin{abstract}
The Brazilian population reaches indices ever higher of elderly. This fact leads us to reflection on the importance of this theme in health education approaches in history teaching. Considering health understood as a fundamental human right and as something we built throughout our life conditioning the social, economic and emotional conditions that accompanied us. The objective of this article is to point out issues concerning the importance of the discussion on aging associated with citizenship education. We use as methodology the bibliographic review on the subject based on the construction of theoretical categories health and education for citizenship from references developed by Benevides and liberating pedagogical proposals whose theoretical constructions had as reference the educator Paulo Freire. The inclusion of the aging theme as a tool for health education in history teaching enables us think of individuals committed to their own health and the community as well as the affirmation of dignified life for all and the building of society of respect for human rights.
\end{abstract}

Keywords: Aging. Education in health. Citizenship. Teaching History

\footnotetext{
1 Mestre em Educação (USP). Docente do Centro Universitário São Camilo-SP. Professora do Ensino Fundamental e do Ensino Médio e Coordenadora Pedagógica do projeto socioeducativo na comunidade de Heliópolis.
} 


\section{Introdução}

O envelhecimento populacional é um tema amplamente discutido na sociedade em geral e, especialmente nos últimos anos, na sociedade brasileira em particular. A ampliação da discussão em relação ao envelhecimento deve-se ao fato da população mundial alcançar índices cada vez mais elevados de idosos, fenômeno também presente na sociedade brasileira.

Segundo a PNAD (Pesquisa Nacional de Amostras de Domicílios), divulgada em 2012 pelo IBGE (Instituto Brasileiro de Geografia e Estatística), os idosos vivem mais, ocupando uma faixa da população cada vez maior. Os resultados apontam que as pessoas com mais de 60 anos são hoje $12,6 \%$ da população, ou 24,85 milhões de indivíduos.

O relatório final da pesquisa realizada, disponibilizado no site do IBGE, destaca que esse crescimento é proporcionalmente maior quando comparado ao crescimento da população infantil, fato relacionado à queda da taxa de fecundidade, responsável pela redução do número de crianças e à longevidade que contribuí progressivamente para o aumento de idosos na população.

Não podemos deixar de apontar avanços em uma sociedade que oferece cada vez mais perspectiva de vida para a sua população. Porém, temos clareza que essa longevidade é marcada por um corte de classe social, pois sabemos que a qualidade de vida, e consequente aumento da perspectiva dos anos vividos, estão intrinsecamente ligados às condições dignas de moradia, saúde, lazer, trabalho, educação, enfim aos direitos fundamentais para preservação da dignidade humana.

Historicamente, no Brasil, o idoso, bem como suas necessidades específicas, foi tratado como questão privada, de responsabilidade da família, de entidades religiosas ou filantrópicas. Temos um reflexo muito grande no presente dessa nossa trajetória histórica, como, por exemplo, poucas políticas públicas específicas que atendam as consequências do fenômeno crescente de envelhecimento da sociedade brasileira.

São vários fatos que poderíamos apontar, porém, um olhar, mesmo que rápido sobre as condições de atendimento à saúde do idoso no SUS (Sistema Único de Saúde), a questão previdenciária, bem como a constatação do predomínio da filantropia no acolhimento de idosos fragilizados e sem possibilidade de 
permanência com familiares, já nos dá uma boa medida em relação aos reflexos a que nos referimos.

Considerando que a maior parte das pessoas com mais de 60 anos vive em áreas urbanas (PNAD 2012), podemos ainda apontar as questões de infraestrutura das cidades, muito aquém de atender as necessidades específicas desta faixa etária no que diz respeito ao transporte, acesso ao lazer e à cultura e aos mais variados espaços que podemos explorar em nossa vida cotidiana. Dessa forma, a lógica do isolamento e da solidão ainda marca a vida de vários idosos nos dias de hoje.

Enfim, são vários os obstáculos que dificultam o envelhecimento saudável de nossa população, mesmo a despeito do Estatuto do Idoso que passou a vigorar em 2003.

Essa constatação nos remete para os problemas estruturais da sociedade brasileira contemporânea, chegando, inclusive, a comprometer as bases sobre as quais se consolida a democracia em curso desde a década de 1980. Assinala, na mesma proporção, a ausência de um Estado de Direito que garanta efetivamente o acesso a todos os grupos a terem garantidos seus direitos, ou dentro da concepção de Hannah Arendt (2007), não obstante para discutir outras questões, o direito a ter direitos. Assim sendo, em consonância com estas transformações no perfil populacional, há no cenário nacional crescentes discussões, principalmente no final do século XX e início do XXI, acerca dos direitos da pessoa idosa, incluindo a necessidade de repensarmos o papel do Estado e suas Políticas Públicas que efetivem a garantia desses direitos.

Não podemos omitir também a questão da violência doméstica e o preconceito, reflexos das representações carregadas de atributos depreciativos em relação à "velhice", enraizadas no imaginário social coletivo.

Neste sentido, ao lado de ações por parte do Estado para a promoção da saúde e bem-estar dos idosos, precisamos debater e pensar em ações que envolvam a todos, bem como que nos torne menos preconceituosos em relação à idade cronológica e à vida após a aposentadoria, e que encaremos nosso envelhecimento de forma mais positiva e saudável. Assim, destacamos a urgência da área de educação discutir de forma mais sistemática essa questão, elaborando 
propostas para que o tema do envelhecimento entre nas escolas e nos currículos dos vários segmentos e das várias disciplinas da educação básica.

Como aponta o Parâmetro Curricular que trata da Saúde como tema transversal:

Na vida cotidiana, a valorização das práticas solidárias diante de problemas e necessidades de saúde dos demais, as atitudes de ajuda e proteção a pessoas doentes e deficientes também se incluem na formação de comportamentos saudáveis. A solidariedade diante das necessidades das pessoas e da comunidade é um ato de humanização e um elemento essencial para o exercício da cidadania. (PCN, 1997, p.261)

Portanto, o objetivo do presente artigo é apontar algumas reflexões relativas à importância de pensarmos iniciativas que incorporem a discussão sobre o envelhecimento como instrumento para Educação em saúde no Ensino de História, a partir dos pressupostos da educação para a cidadania, visando a alteridade e respeito às diferenças, que atenda a todos com dignidade nesta etapa da vida.

\section{Avanços do ponto de vista da Lei e suas implicações para a área da educação em geral e para a Educação em Saúde no Ensino de História, em particular}

Mônica de Ávila Todaro (2009), em seu livro: Vovô vai à escola - a velhice como tema transversal no ensino fundamental, destaca a presença na legislação brasileira de dispositivos específicos à inclusão da temática do envelhecimento no âmbito educacional em seus vários segmentos.

Ressalta, por exemplo, o documento legal PNI (Política Nacional do Idoso) que em seu capítulo IV menciona a necessidade dos currículos, nos diversos níveis de ensino, conterem conteúdos relativos ao processo de envelhecimento. Conteúdos estes que contemplem a disseminação do conhecimento sobre o assunto, e tenham o objetivo de eliminação do preconceito presentes nas relações intergeracionais. 
Destacamos, ainda, a principal lei que temos em nosso país para essa fase da vida que é o Estatuto do Idoso, Lei n. 10.741/2003, que em seu artigo 22 expressa:

Nos currículos dos diversos níveis de ensino formal serão inseridos conteúdos voltados ao processo de envelhecimento, ao respeito e à valorização do idoso, de forma a eliminar o preconceito e a produzir conhecimentos sobre a matéria.

Horácio Wanderlei Rodrigues, ao analisar esse dispositivo legal, observa três objetivos:

a) educar os mais jovens para a aceitação dos idosos, permitindo assim a sua adequada integração familiar e social; esse aspecto dever ser priorizado na educação básica; b) educar todos nós, seres humanos, para aceitarmos o processo de envelhecimento e nos prepararmos adequadamente para a terceira idade; c) desenvolver o processo de envelhecimento, em todos os seus aspectos, produzindo novos conhecimentos sobre essa matéria. (2005, p. $62)$.

A legislação mostra-nos a necessidade e urgência da questão e sugere a proeminência da temática focada em todos os segmentos educacionais, desde a Educação Infantil. Porém, sabemos que, mesmo a despeito da legislação, ainda não incorporamos a temática nos currículos escolares, quando muito, encontramos trabalhos pontuais e não sistematizados com tal enfoque.

O ensino de História pode contribuir de forma relevante, contemplando em seu currículo um diálogo com a educação em saúde, a partir da temática do envelhecimento, incorporando discussões e metodologias que possibilitem a apreensão crítica, por parte de nossos educandos, de questões relacionadas à saúde, previdência, seguridade social, enfim de políticas públicas efetivas para esta faixa etária.

O PCN que trata da saúde como tema transversal coaduna com os pressupostos acima defendidos tornado a discussão acerca do envelhecimento adequada aos seus propósitos e objetivos. Destacamos no documento:

A promoção da saúde ocorre, portanto, quando são asseguradas as condições para a vida digna dos cidadãos, e, especificamente, por meio da educação, da adoção de estilos de vida saudáveis, do desenvolvimento de aptidões e capacidades individuais, da 
produção de um ambiente saudável, da eficácia da sociedade na garantia de implantação de políticas públicas voltadas para a qualidade da vida e dos serviços de saúde. (1997, p.255)

Não podemos esquecer que ao incorporar o diálogo com a educação em saúde e ensino de História, entendemos o conceito de saúde associado ao um direito humano fundamental e como algo que construiremos ao longo de nossas vidas, condicionada às condições sociais, econômicas e emocionais que nos acompanharam.

Neste sentido, o ensino de História necessariamente incorporará o olhar sobre a trajetória de vida, como nos aponta Minayo (2011, p. 9), ao afirmar:

\begin{abstract}
Como se pode deduzir, a referência etária abrange uma população, que recobre um intervalo vital no mínimo de 30 anos, constituído por pessoas que construíram e constroem uma trajetória de vida muito diferenciada do ponto de vista subjetivo e social, como é o viver nas cidades ou nas regiões rurais, pertencer à determinada classe social ou etnia, ser do sexo feminino ou masculino, ter determinada opção sexual e possuir determinado nível educacional.
\end{abstract}

Não podemos deixar de chamar atenção sobre a necessidade de incorporamos, ao longo destas abordagens acima referidas, reflexões críticas sobre as representações cristalizadas em nossa sociedade acerca da velhice, possibilitando a desconstrução hegemônica de associá-la a uma fase de decadência e improdutividade. Obviamente, com o bom senso, como aponta Minayo (2011) de não cair no discurso ideológico, com finalidades meramente mercadológicas, enfatizando a velhice como a melhor idade.

A mesma autora afirma: "o próprio Estado promove um imaginário que aterroriza os idosos, pois os coloca como responsáveis pelos desequilíbrios da Previdência, das políticas sociais e de saúde." (2011, p. 13).

Dessa forma, o discurso da melhor idade, em uma sociedade que caminha aceleradamente para uma modelo de Gestão do Estado a partir dos pressupostos neoliberais, pode servir enquanto justificativa de retirada dos direitos, mesmos os parcos diretos previdenciários hoje existentes. 


\section{A problemática da Cidadania e o olhar em relação ao processo de envelhecimento e a "velhice": possibilidades e compromissos no diálogo entre Educação em Saúde e ensino de História.}

Como apontamos anteriormente, 0 fato de termos conquistado mais longevidade em nossa sociedade não pressupõe que tenhamos conquistado condições dignas para viver essa longevidade.

No Brasil, o Estado, criado dentro de um viés clientelista e patrimonialista, dirigindo suas ações para determinados grupos e em consonância com estes grupos, sedimentou a relação hierárquica existente no todo social. Questões fundamentais como Cidadania, Estado de Direito, Justiça Social apareceram como privilégios de poucos, conforme sustenta Marilena Chauí (1996). Dessa forma, as relações sociais se efetivaram na base da tutela e do favor. A própria noção de direitos passou a ser concebida como dádiva do Estado e dos grupos dominantes.

Quando falamos dos idosos essa problemática torna-se mais aguçada, haja vista a vulnerabilidade a que estão sujeitos diante das precárias políticas de saúde, moradia, previdência e assistência social.

As recentes conquistas - no que diz respeito aos direitos dos idosos reconhecidos no âmbito da Lei - precisam ganhar visibilidade em todo o tecido social. Os diferentes indivíduos, independentemente de sua faixa etária, necessitam ter clareza da legitimidade dos direitos que garantem a efetivação da cidadania em geral e dos idosos em particular, engajando-se, dessa forma, em movimentos da sociedade civil que buscam a participação nas discussões e construção de políticas públicas que atendam aos direitos dos idosos, portanto, de todos nós.

Neste ponto da discussão, julgamos que se torna claro o papel da educação, pois espaços para afirmação e conquistas de direitos só se efetivam em sociedades em que o sentido e significado da cidadania fazem-se presentes. Ademais, a temática do envelhecimento, no diálogo entre educação em saúde e ensino de história, pressupõe e é parte constituinte da educação para a cidadania. Bem como, atende ao objetivo contido no PCN que trata a saúde como tema transversal, a saber: "compreender saúde como direito de cidadania, valorizando as ações voltadas para sua promoção, proteção e recuperação". (1997, pg.269) 
Dentro desta perspectiva devemos indicar também que a afirmação da cidadania e comprometimento com os direitos da pessoa idosa só é possível a partir da construção de outro olhar em relação ao processo de envelhecimento e a "velhice", um olhar para além do consenso presente em sociedades como a nossa pautada pela lógica do capital. Para tornar a discussão mais clara podemos apontar algo que é extremamente evidente a todos nós, como, por exemplo, a supervalorização da juventude presente em nosso imaginário social, pois esta representa a idade da produtividade, valor maior da lógica capitalista.

Como afirma Mônica Todaro:

\begin{abstract}
O bem-estar e a aceitação social dos indivíduos aparecem sempre associados a um corpo belo e jovem. As imagens veiculadas pelos meios de comunicação transformam os atributos e os valores juvenis em ideal de vida para todas as idades. O mundo internalizado é o da juventude, do consumo, do descartável, da individualidade e do ritmo frenético. Esse ideário vem se apresentando aos indivíduos como objetivos para que atinjam o modelo de juventude eterna. (2009, p. 13).
\end{abstract}

Neste sentido, predomina em nosso imaginário social a desvalorização dos indivíduos conforme sua faixa etária que está ligada à lógica da produtividade, promovendo atitudes e posturas negativas diante ao processo de envelhecimento, assim como, o olhar que temos em relação ao idoso, especialmente na era do capitalismo globalizado, conforme análise de Angela Mucida:

Junto à nova ciência, inaugura o imperativo do novo sob diferentes formas, tanto no tocante aos objetos fabricados pelo capitalismo moderno quanto à imagem e à decapitação da história. Quando tudo se torna obsoleto num tempo mínimo, é o próprio sujeito que está em causa: envelhecer torna-se também obsoletar. (2006, p. 80)

Apontamos novamente o papel fundamental do diálogo entre o ensino de história e educação para o envelhecimento durante toda a Educação Básica, a partir dos referenciais aceitos pela Organização Mundial da Saúde (OMS) como entendimento do conceito de saúde de forma ampla e abrangente, presentes também nos Parâmetros Curriculares Nacionais. Ao longo deste documento, encontramos explicitamente afirmações que corroboram com o que propomos neste artigo. 
Intricados mecanismos determinam as condições de vida das pessoas e a maneira como nascem, vivem e morrem, bem como suas vivências em saúde e doença. Entre os inúmeros fatores determinantes da condição de saúde, incluem-se os condicionantes biológicos (sexo, idade, características pessoais eventualmente determinadas pela herança genética), o meio físico (que abrange condições geográficas, características da ocupação humana, fontes de água para o consumo, disponibilidade e qualidade dos alimentos, condições de habitação), assim como o meio socioeconômico e cultural, que expressa os níveis de ocupação e renda, o acesso à educação formal e ao lazer, os graus de liberdade, hábitos e formas de relacionamento interpessoal, as possibilidades de acesso aos serviços voltados para a promoção e recuperação da saúde e a qualidade da atenção por eles prestada. [...]

Acreditar que cidadania é exercício de sujeitos do processo saúde/doença é a motivação essencial da educação para a saúde. Esta é a concepção de saúde que fundamenta os Parâmetros Curriculares Nacionais de Educação para a Saúde. (1997, p.251)

\section{Educação para a Cidadania como agente de mudança de atitudes em relação ao envelhecimento e à "velhice"}

A Educação formal é primordial para uma mudança de postura e atitudes em relação ao envelhecimento e à velhice, pois:

Qualquer princípio com finalidade educativa de grande abrangência deve ter garantido seu espaço no meio escolar, que acessa a grande maioria dos cidadãos em formação, as crianças, além de adolescentes e adultos, num ambiente propício à pesquisa, discussão, análise, reflexão e difusão de conhecimentos. (BUSMANN, 2009, p.1)

Mas, nosso esforço durante a construção do presente artigo é defender que somente a inclusão da temática do envelhecimento sem os pressupostos que apresentamos no item anterior acaba por legitimar, de certa forma, o discurso apenas do direito à diversidade (etária, étnica, gênero, cultural), desde que as pessoas com diferenças que são pobres, aceitem permanecer nos espaços sociais que foram construídos para as camadas populares. (SACAVINO, 2008). Pensar a temática do envelhecimento é pensar também nas relações entre pobreza e envelhecimento e envelhecimento e política, destarte a partir da educação para a cidadania. 
Entendemos a construção da categoria teórica cidadania e educação para a cidadania a partir dos referenciais desenvolvidos por Maria Victoria Benevides (2001), ou seja, a cidadania como uma junção de direitos políticos (participação na vida pública), direitos sociais, econômicos e culturais.

Acreditamos que o ensino de História tem um papel importante na construção de sujeitos participantes e críticos. Portanto, instrumentalizados no sentido de exercer sua participação efetiva no espaço público, seja por meio da autonomia diante das escolhas, seja na inserção nos espaços de intervenção do poder.

Mas, como bem salienta Benevides, esta educação que contemple tal propósito precisa necessariamente conter certas características que a autora denomina de educação para a Democracia que, ao proporcionar valores e conhecimentos, capacite e encoraje os sujeitos a exercerem ativamente sua cidadania: condição mais que necessária para o aperfeiçoamento e proteção de uma sociedade democrática com respeitos as diferenças do ponto de vista étnico, de gênero e de faixa etária.

A autora parte dos seguintes conceitos de democracia, cidadania e educação:

[...] são premissas, no sentido de uma opção teórica, a começar por democracia, aqui entendida como regime político fundado na soberania popular e no respeito integral aos direitos humanos. Esta breve definição tem a vantagem de agregar democracia política e democracia social, liberdade e justiça [...] Educação é entendida, basicamente, como a formação do ser humano para desenvolver suas potencialidades de conhecimento, de julgamento e de escolha para viver conscientemente em sociedade, o que inclui também a noção de que o processo educacional, em si, contribui tanto para conservar quanto para mudar valores, crenças, mentalidades, costumes e práticas. (1996, p. 225).

Acreditamos que uma prática educativa com tais propósitos está ligada diretamente às propostas pedagógicas libertadoras, cuja construção teórica teve como referência o educador Paulo Freire. Assim como Benevides, Freire, em suas obras, coloca que o fazer educativo pode contribuir para reforçar a sociedade dividida em classes ou questionar o sistema e atuar de forma compromissada para ajudar em sua transformação. A educação libertadora deixa claro seu projeto histórico, ou seja, a formação para a ação coletiva, planejada e organizada em 
direção à transformação do social, partindo das mudanças ao nível do cotidiano para mudanças cada vez mais abrangentes e socialmente efetivas.

Numa relação direta com a construção e a prática da cidadania, as propostas educativas que buscam a conscientização para a participação, partem do pressuposto que nossa vocação é de sermos sujeitos e não objetos. Só podemos ser sujeitos se, refletindo sobre nossas condições de estar no mundo, assumimos o compromisso com esta realidade, "da qual, porque é sujeito, não deve ser simples espectador, mas deve intervir cada vez mais." (FREIRE, 2001, p. 40). Poder pensar e discutir com outros sujeitos sobre nossa realidade, nossos desejos e as condições reais de realização desses é um primeiro passo para a construção de um projeto pessoal e coletivo de cidadania. Nesse processo acontece a valorização do humano, com possibilidade de participar e usufruir em condições de igualdade das conquistas sociais, como a longevidade e o direito a um envelhecimento digno, bem como viver a "velhice" com dignidade.

Ainda numa perspectiva freiriana, enfatizamos a importância da ética neste processo educativo. Exatamente por nós, homens e mulheres, sermos seres inconclusos, em constante formação, estamos, enquanto sujeitos históricossociais, sempre intervindo, escolhendo, decidindo... "por tudo isso, nos fazemos seres éticos." (FREIRE, 2000, p. 34).

Nessa mesma linha de reflexão, Benevides enfatiza a rejeição a qualquer forma de discriminação, afirmando que "a prática preconceituosa de raça, de classe, de gênero e de faixa etária ofende a substantividade do ser humano e nega radicalmente a democracia." (1996, pg. 40).

O educando, para mudar sua percepção e atitude diante do processo de envelhecimento e da "velhice", precisa de oportunidades para vivenciar experiências que promovam o debate sobre o idoso e questões intergeracionais, que despertem o interesse pelo "outro idoso", que se coloquem no lugar deles e entendam que existem diferentes modos de viver a velhice, principalmente a partir de uma perspectiva que enfoque o corte de classe social, sem desconsiderar, obviamente, mas, não se esgotando nas diferenças étnicas e de gênero.

Acerca da metodologia o PCN que trata da saúde como tema transversal, enfatiza que "na educação para a Saúde o papel mais importante do professor é o de motivador que introduz os problemas presentes, busca informação e materiais 
de apoio, problematiza e facilita as discussões por meio da formulação de estratégias para o trabalho escolar. (1997, pg. 261)

Abordando a interdisciplinaridade na abordagem do envelhecimento, a Professora Guiomar Lopes, do Departamento de Medicina Preventiva da Unifesp, aponta:

Homens e mulheres sofrem perdas, preconceitos e estereótipos, mas os recursos com que contam para enfrentar a velhice são diferentes. As mulheres se deparam nesta fase com questões acumuladas ao longo de uma vida de discriminação e desigualdades estruturais. (...) As diferenças e similitudes nos velhos nos remetem à reflexão de que a construção das identidades passa pelo diálogo interdisciplinar, que é um recurso imprescindível para a compreensão do processo. (LOPES, 2011, p.23).

Nessa mesma direção, Ana Brêtas e Anderson Rosa, (2011, 194), discutindo a questão do envelhecimento em situação de rua, afirmam: "Considerando a heterogeneidade das sociedades, defendemos que as diversidades de gênero, de classe social e de etnia precisam também ser analisadas, pois são os responsáveis pela delimitação do espaço social que o indivíduo ocupa na sociedade.".

Estes mesmos autores concluem no final de suas reflexões:

Pensar a velhice em situação de rua nos remete a refletir sobre a sociedade capitalista; portanto, a partir da consciência de que a divisão social e sexual não é fruto do acaso, mas resultado das iniquidades previstas nesta forma de organização social. (ROSA \& BRÊTAS, 2011, p. 194).

Este reconhecimento do outro e de si como sujeito de direitos amplia o sentido de pensar o processo de envelhecimento de forma mais positiva e a partir da lógica, não só do cuidado e responsabilidade em relação ao seu envelhecer, mas de toda a sociedade comprometida com esse processo que passa a ser algo construído, conquistado passo a passo. Não uma coisa abstrata que é prometida sem ser entendida e nem vivenciada por não se saber lidar com ela.

No papel de educadores, se proporcionamos essa experiência, estamos inserindo os educandos num processo de construção de uma percepção mais humanizadora diante do envelhecimento e da luta política para concretização material dos direitos à uma "velhice" vivida com dignidade, independente das 
diferenças econômicas, étnicas e de gênero. Na sociedade, a conquista de direitos, em qualquer âmbito, se fez e se faz por meio da busca coletiva por melhores condições de vida.

Acreditamos que pensar a inclusão da temática do envelhecimento nos currículos do ensino de história, dialogando transversalmente com a educação em saúde, a partir da educação para cidadania que defendemos, nos possibilita pensarmos em crianças, adolescentes e adultos comprometidos com a afirmação da vida, da dignidade. Comprometimento que invoca o desenvolvimento responsável e consciente de um posicionamento crítico e denunciador frente a toda e qualquer ameaça à vida digna para todos e á edificação de uma sociedade de respeito aos direitos humanos.

Finalizamos nossa contribuição para a discussão dessa temática com a lúcida descrição da velhice feita por Simone de Beauvoir:

\begin{abstract}
A velhice não é um fato estático; é o resultado e o prolongamento de um processo. Em que consiste esse processo? Em outras palavras, o que é envelhecer? Esta ideia está ligada à ideia de mudança. Mas a vida do embrião, do recém-nascido, da criança é mudança contínua. Caberia concluir daí, como fizeram alguns, que nossa existência é uma morte lenta? É evidente que não. Um tal paradoxo desconhece a essencial verdade da vida; esta é um sistema instável no qual, cada instante, o equilíbrio se perde e se reconquista: é a inércia que é sinônimo de morte. Mudar é a lei da vida. (1990, pg. 17).
\end{abstract}

\title{
Referências
}

ARENDT, H. A origem do Autoritarismo. São Paulo: Cia das Letras, 1980.

BEAUVOIR, S. de. A velhice. Rio de Janeiro: Nova Fronteira, 1990.

BENEVIDES, M. V. Cidadania Ativa. São Paulo: Ática, 1991.

- Cidadania e Direitos Humanos. (Texto revisto de palestra na Universidade de São Paulo), USP, São Paulo, outubro de 2001. out. 1996.

Educação para a Democracia. Revista Lua Nova, São Paulo, n. 34, p. 46,

BOURDIEU, P. A Juventude é apenas uma palavra. In: Questões de

Sociologia. Rio de Janeiro: Marco Zero, 1983. 
BRASIL. Lei Federal 10.741, de 1 de outubro de 2003. Estatuto do Idoso. Brasília: Congresso Nacional, 2004.

BRASIL. Ministério da Educação e do Desporto- Secretaria de Educação Fundamental. Parâmetros Curriculares Nacionais- Terceiro e Quarto Ciclos: Temas Transversais. Brasília: Secretaria de Educação Fundamental, 1998.

BUSMANN, B. M. S. Projeto Envelhecer. Paraná, CEDI, 2009.

CHAUÍ, M. Conformismo e Resistência. São Paulo, Brasiliense, 1996.

EDA, E. de J. Procurando superar a modelização de um modo de envelhecer. Revista Movimento. Porto Alegre, v. 10, n.2, p.57-71, maio/agosto. 2004.

ELIAS, N. A solidão dos moribundos seguido de envelhecer e morrer. Rio de Janeiro: Jorge Zahar, 2001.

FREIRE, P. Ação Cultural Para a Liberdade e outros escritos. Rio de Janeiro: Paz e Terra, 2001.

. Educação e Mudança. Rio de Janeiro: Paz e Terra, 1979.

. Pedagogia da Esperança: um encontro com a Pedagogia do Oprimido. Rio de Janeiro: Paz e Terra, 1992.

Pedagogia da Autonomia: Saberes necessários à prática educativa. São Paulo, Rio de Janeiro, Paz e Terra, 2000.

. Política e Educação. São Paulo: Cortez, 2001.

2001.

. Conscientização: Teoria e Prática da Libertação. São Paulo, Centauro:

Instituto Brasileiro de Geografia e Estatísticas- Pesquisa Nacional por Amostra de Domicílios (Pnad), 2012. Disponível em: www.ibge.org.br.

LOPES, S. G. Envelhecimento e Interdisciplinaridade: uma prática em construção. In: TRENCH, B., ROSA, T. E. (Org.). Nós e o Outro: envelhecimento, reflexões, práticas e pesquisa. São Paulo: Instituto de Saúde, 2011, p.21-34.

MAZUTTI, C.; SCORTEGAGNA, H. de M. Velhice e envelhecimento humano: concepções de pré-escolares do município de Tapejara- RS. Revista Brasileira de Ciências do Envelhecimento Humano. Passo fundo, n. 4, p.101- jul/dez. 2006.

MERCADANTE, E. Aspectos Antropológicos do Envelhecimento. In: NETTO, M. P. (Org.). Gerontologia: a velhice e o envelhecimento em visão globalizada. São Paulo: Atheneu, 1996.

MINAYO, M. C. Envelhecimento demográfico e o lugar do idoso no ciclo da vida brasileira. In: TRENCH, B., ROSA, T. E. (Org.). Nós e o Outro: envelhecimento, reflexões, práticas e pesquisa. São Paulo: Instituto de Saúde, 2011, p.7-16. 
MUCIDA, Â. A velhice no mal-estar da cultura. In: envelhece: psicanálise e velhice. 2 ed. Belo Horizonte: Autêntica, 2006.

PEIXOTO, C. E. Entre o estigma e a compaixão e os termos classificatórios: velho, velhote, idoso, terceira idade. In: BARROS, Myriam M. L. de (org.) Velhice ou Terceira Idade? Estudos Antropológicos sobre identidade, memória e política. Rio de Janeiro: FGV, 1998.

PIRES, L. S.; LIMA, S A. de S. da C. O Pedagogo e a Pedagogia do Envelhecer. Revista Fragmentos de Cultura. n. 3-4, p. 403, mar/abr. 2007.

RODRIGUES, Horácio Wanderley. Educação Para a Terceira Idade. Revista Aprender. Marília, n.27, p.62, nov./dez., 2005.

ROSA, A. da S., BRÊTAS, A. C. P. Envelhecimento em situação de rua: a história de Maria Rosa. In: TRENCH, B., ROSA, T. E. (Org.). Nós e o Outro: envelhecimento, reflexões, práticas e pesquisa. São Paulo: Instituto de Saúde, 2011, p.183-198.

SACAVINO, S.; CANDAU, V. M. (Org.). Educação em Direitos Humanos: Temas, questões e propostas. Petrópolis: DP ET Alli Editora, 2008.

SANTOS, W. G. dos. Cidadania e justiça. Rio de Janeiro: Campus, 1979.

TODARO, M. DE A. Vovô vai à escola: a velhice como tema transversal no ensino fundamental. Campinas: Papirus, 2009. 